\section{Occupied territory}

\section{Randall White}

The Palaeolithic Settlement of Europe. By Clive Gamble. Cambridge University Press:1986. Pp. 469. Hbk £40, \$65; pbk $£ 15, \$ 24.95$.

AcCording to current evidence, Europe was first occupied by hominids 1.5 million years after the first Palaeolithic toolmakers emerged in Africa. There is much that remains to be known about this successful expansion of our species into northern latitudes, but there is also much information presently available. Research on the Palaeolithic settlement of Europe (roughly $750,000-12,000$ years ago) is published in so many languages, and is based upon such a variety of theories, that it is difficult for any scholar to have a clear overall view of the subject. Clive Gamble's drawing together of knowledge and references from such an intellectual mosaic is in itself a great achievement.

It must be said, however, that the framework on which the book is organized is puzzling, if not idiosyncratic. The first chapter, which begins with a history of European Palaeolithic studies, concludes with a strong advocacy of Binfordian methodological premises. While Binford has had a very positive influence on European Palaeolithic studies, it is a little surprising to find his views uncritically repeated virtually word for word.

The following chapter, "HunterGatherer Regional Systems", takes a detailed look at regional and inter-regional adaptations among contemporary huntergatherers. At the end of it, Gamble follows Robert Foley in proposing rejection of the site as an analytical unit for the study of prehistoric hunter-gatherers. This has become a popular position recently; but it deserves much closer scrutiny in light of the fact that sites do correspond to palimpsests of past living communities, a concept critical to regional studies of living peoples. I found this chapter especially troublesome in its heavy emphasis on 1960 s ecological thinking. The result is a form of ecological functionalism which views the social world of huntergatherers exclusively with reference to the imputed functions of "alliance" and "information strategies". Anthropological theory in the 1980 s is not what it was in the 1960 s, and for Gamble to cite Marshal Sahlins's ideas of 1968, without acknowledging Sahlins's refutation of the ecological paradigm, betrays an unduly selective approach.

Chapter 3 is a complex presentation of data on environments and resources. Gamble breaks Europe down into nine sub-regions, upon which are based the inter-regional comparisons in the rest of the book. Discussion of glacial chronology is detailed and excellent. Also here is a listing of the key anatomical and behavioural attributes of the main faunal species, which is very helpful but unfortunately omits certain attributes of importance to human beings, such as hide and antler quality and aggregation behaviour.

In the next, very short chapter, entitled "Technological and Typological Approaches", Gamble explores technological and typological evolution during the European Palaeolithic. The result is a severe revision of the traditional sequence in which the present Middle and Lower Palaeolithic are melded to form the "Early Palaeolithic", which comprises all industries before 35,000 years ago. The terms Lower and Middle Palaeolithic are inadequate, and Gamble's lumping of the periods together clears the decks for future analyses of much potentially interesting variation. It is all the more curious, then, to see him become a splitter when he turns his attention to the Upper Palaeolithic, creating two divisions (before and after 20,000 years BP). The later division is based upon the emerging importance of microliths after 20,000 years BP. Unfortunately, it ignores recent excavations in which Aurignacian (caminade scrapers) and Gravettian (microgravettes, backed bladelets) levels have yielded abundant microliths.

Chapter 5 is a useful, well-referenced discussion of the data base for research on Palaeolithic Europe, organized according to Gamble's newly developed temporal and geographical structure. Each region is summarized according to (1) chronology, (2) industrial groupings, (3) geographical variation and regional case-studies, and (4) burials and art (though the last of these is rather sketchy).

The sixth chapter, "Space and Subsistence", is the best in the book and probably the most comprehensive account of Palaeolithic settlement and subsistence patterns that has appeared to date. There are two shortcomings, however. First, because of its supposed circularity sitelocation research is summarily dismissed. Second, after having illustrated some brilliant work on intra-site spatial patterns, Gamble re-states his view that the site should not be our focus of analysis. My position is that the examination of individual sites must be used to build a regional picture of human landscape use.

"Demography and Style", the next chapter, is puzzling, because the section on demography deals almost exclusively with carnivore behaviour as a basis for research into the distribution of populations in space. The section on style and interaction relies heavily on information approaches to variability in material culture, exemplified by Gamble's own work on Gravettian female figurines. Again, in true 1960s fashion adaptive significance is attributed to form in portable and cave art; based upon a very narrow reading of the Australian literature, the latter is treated as territorial marking rather than as evidence for complex systems of meaning that help to define the very nature of human adaptation.

Chapter 8, "Society, Sediments and Settlement", emphasizes the interesting regional differences in stone-tool and site densities. Here, Gamble wishes to chip away at the notion that a universal set of Upper Palaeolithic traits, rather than local environmental exigencies, conditioned the archaeological record in all regions. This is indeed an important issue, but Gamble's density calculations need to be examined closely before being accepted. For example, his find-spot density for the Perigord is based on a surface area of 12,600 square kilometres, approximately twice the true figure. Moreover, historical differences in the intensity of site search need to be taken into consideration. It is a pity that Gamble fails to suggest the need for systematic controlled survey to control sample quality in assessing overall population increase across the transition between the Middle and Upper Palaeolithic.

In the concluding chapter, the virtues of viewing culture as an adaptive process are extolled, especially as applied to the emergence and diversification of culturally modern humans at about 35,000 years BP. Gamble seems not to recognize that those of us who view the Upper Palaeolithic as an evolutionary threshold are not anti-adaptive; rather, we are comfortable in switching back and forth between discussion of the evolution of culture and the evolution of cultures.

More disturbing in the conclusion, however, are the peculiarities that emerge in the form of three models for what human beings did when they reached Europe. The problem posed by cold northern climates is viewed primarily as a problem of finding a niche, which ignores clothing, fire and shelter as cultural evolutionary prerequisites. In any event, Gamble proceeds to propose that the earliest Europeans were adapted to the consumption of frozen animal carcasses resulting from natural deaths in autumn and winter. $\mathrm{He}$ seriously suggests that the wooden "spears" from Lehringen and Clacton were probes for finding dead animals beneath the snow. This is an unfortunate excursion onto the fringe.

While readers must work around some awkward theoretical and organizational impediments, the rich (though already somewhat dated) documentation and firstclass presentation of this book will make it a basic reference in English-language Palaeolithic studies for years to come.

Randall White is an Assistant Professor in the Department of Anthropology, New York University, New York, New York 10003, USA. 